\title{
Evaluation of New Compounds Efficacy on Dermatophytosis Treatment in Cattle and Buffalo
}

\author{
Walid S Mousa*1 and Eman Abdeen E ${ }^{2}$ \\ ${ }^{1}$ Department of Animal medicine and Infectious diseases, University of Sadat City, Egypt \\ ${ }^{2}$ Department of Bacteriology, Mycology and Immunology, University of Sadat City, Egypt
}

Submission: June 18, 2018; Published: August 14, 2018

*Corresponding author: Walid S Mousa, Department of Animal medicine and Infectious diseases, Faculty of Veterinary Medicine, University of Sadat City, 32897, Egypt, Email: walidsaadvet@yahoo.com

\section{Abstract}

Dermatophytosis is superficial fungal infection of the hairs and outer layers of the skin caused by specialized group of fungi named dermatophytes. Dermatophytosis is worldwide zoonotic disease responsible for high economical losses in farm animals due to skin damages especially in the winter. Several compounds had been used for dermatophytosis treatment such as a chlorhexidine, salicylic acid, iodinecontaining shampoos and tinctures, griseofulvin, thiabendazole and ethylenediamine dihydriodide; some of these treatments have been reported to be ineffective or even toxic to the host. Therefore, in this study we evaluate the efficacy of clove oil and local prepared culture filtrate vaccine on treatment of ringworm cases in cattle and buffaloes. Fifty diseased animals (cattle no; 30 and Buffalo no 20) had been treated with both preparations. The clove oil used as pure oil as topical spray 3 times daily for 10 successive days on the affected lesions. The culture filtrate vaccine used as suspension injected $\mathrm{S} / \mathrm{C}$ with dose of $5 \mathrm{ml}$ and second dose 10 days later in. The results indicate strong antifungal action of clove oil and complete healing of ringworm lesions within 2 weeks as well as culture filtrate vaccine was effective therapy as emergency treatment in injectable form.

Keywords: Ringworm; Clove oil; Culture filtrate; Dermatophytosis; Trichophyton; Microsporum; Epidermophyton; Ectothrix; Eugenol; Endothrix; Cows; Buffaloes; Actidion

\section{Introduction}

Ringworm or known as dermatophytosis is contagious fungal disease caused by dermatophytes species affecting both animals and human that mainly damage the superficial layer of skin, hair, nails and claw [1]. Only, three genera (Trichophyton, Microsporum and Epidermophyton) are known to be pathogenic for both human and animals [2]. Recently the high incidence of fungal infection mainly attributed to intensive use of immunosuppression drugs in man and poorly maintenance condition surrounding animals [3]. The diseased animals, infected fomites and contaminated environment act as main source and reservoir for infection among susceptible hosts throw direct or indirect contact [4]. The disease prevalent more predominant in poorly closed contact housed animals which help in disease dissemination [5].

In particularly, the worm humid climate countries as in Africa and Egypt are favorable for spore formation and consequently highly infection [6]. Dermatophytosis mainly observed in young calves, which have high skin $\mathrm{PH}$ and immune system is ill developed [7]. The increasing in resistance to antifungal drugs had led for emergence of new compounds to avoid the toxic effects of traditional antifungal drugs. For a long time, Clove oil was widely used as antiseptic, analgesic and anesthetic agent especially in dental practice [8]. Moreover [9] had been reported significant and strong antifungal efficacy of Clove oil active ingredient (Eugenol) in treatment of most fungal species including dermatophyes. Recently vaccination model appears to be of value in control and treatment of dermatophytosis in cattle [10]. So, this study aimed to evaluate the antifungal effect of both Clove oil and local prepared culture filtrate vaccine in treatment of dermatophytosis in cows and buffaloes calves under field condition.

\section{Material and Methods}

\section{Clinical Examination and Samples Collection}

Four- hundred animals were clinically examined for ringworm lesions from cows and buffaloes calves from a private feedlot farm in Minufiya governorate, Egypt. Fifty skin scrapings (50) were collected from 250 buffaloes calves and 150 cows' calves (20 and 30 skin scraping) respectively. The age ranged from 6 to 24 months. Clinical examination of affected calves showed clinical signs of ringworm (non-itched lesion of alopecia and/ circumscribed grayish-white, crusty, raised lesions) in ear and around eyes. Each sample was divided into two parts. One part was used for direct microscopic examination. The second 
part was cultured on Sabouraud's dextrose agar (SDA) containing (Chloramphenicol $50 \mathrm{mg} / \mathrm{L}$ and actidion (sigma) $0.5 \mathrm{~g} / \mathrm{L}$ ) with addition of thiamin and inositol and incubation at $37^{\circ} \mathrm{C}$ up to 3 week with daily examination.

\section{Mycological Examination}

\section{Direct Microscopical examination of samples}

According to [11]. Briefly, one drop of $20 \% \mathrm{KOH}$ in a glass slide with skin scraped sample and covered by cover slide with gently heating and left for 1 hour. Then examined under microscope or detection of (hyphea and spores around (ectothrix) or within the hairs (endothrix).

The identification of dermatophytes: through macroscpical identification of colony morphology as described by $[12,13]$ that include the rate of growth, color, texture of the colony or consistency. While Microscopical morphology of the isolates was done by using wet mount preparation [14].

\section{Culture filtrate}

It is prepared according to [15] The isolated strain of
T.verrucosum was inoculated into Erlenmeyer flasks of $500 \mathrm{ml}$ containing $300 \mathrm{ml}$ of Sabouraud,s dextrose broth supplemented with thiamine and inositol, incubated at $37{ }^{\circ} \mathrm{C}$ for $4-6$ weeks. The submerged growth of T. verrucosum was harvested and filtrated with 0.45 um Millipore filter. Then mixed with adjuvant (Montanide) by equal amount and stored at $4{ }^{\circ} \mathrm{C}$.

\section{Antifungal Activity of Clove Oil}

Essential oil: Clove oil was obtained from pharmacology department, National Research Center, Doki, Giza, Egypt, which dissolving in Tween80.

\section{Field Treatment of Dermatophytosis by Colve Oil and Culture Filtrate Vaccine in Infected Cases}

The clove oil used as pure oil as topical spray 3 times daily for 10 successive days on the affected lesions in 15 cases in cows and 8 cases in buffaloes). The culture filtrate vaccine used as suspension injected $\mathrm{S} / \mathrm{C}$ with dose of $5 \mathrm{ml}$ and second dose 10 days later in (10 cases in cows and 7 cases in buffaloes). Five cases from each species were left without treatment to serve as control cases.

\section{Discussion}

Table 1: Prevalence of dermatophytosis in cattle and buffaloes in relation to $\mathrm{KOH}$ and culture examination.

\begin{tabular}{|c|c|c|c|c|c|c|c|}
\hline Total Number & Positive in Clinical Examination & $\mathbf{\%}$ & Positive in $\mathbf{K O H}$ & $\mathbf{\%}$ & Positive in Culture & \% & 73.3 \\
\hline Cattle & 150 & 30 & 20 & 22 & 14 & 46.7 \\
\hline Buffaloes & 250 & 20 & 8 & 12 & 60 & 9 & 45 \\
\hline Total & 400 & 50 & 12.5 & 25 & - & 17 & - \\
\hline
\end{tabular}

Table 2: Results of treatment of dermatophytosis by clove oil and culture filtrate in cows and buffaloes.

\begin{tabular}{|c|c|c|c|c|c|c|c|}
\hline $\begin{array}{c}\text { Animal } \\
\text { Species }\end{array}$ & $\begin{array}{c}\text { Infected } \\
\text { Cases }\end{array}$ & $\begin{array}{c}\text { No of Animals } \\
\text { Treated by Clove Oil }\end{array}$ & $\begin{array}{c}\text { No of Cured } \\
\text { Animals }\end{array}$ & $\begin{array}{c}\text { \%of Cured } \\
\text { Animals }\end{array}$ & $\begin{array}{c}\text { No of Animals Treated } \\
\text { by Culture Filtrate }\end{array}$ & $\begin{array}{c}\text { No of Cured } \\
\text { Animal }\end{array}$ & $\begin{array}{c}\text { \%of Cured } \\
\text { Animal }\end{array}$ \\
\hline Buffaloes & 20 & 8 & 7 & $87.5 \%$ & 7 & 5 & $71.4 \%$ \\
\hline cows & 30 & 15 & 12 & $80 \%$ & 10 & 7 & $70 \%$ \\
\hline
\end{tabular}

A
Figure 1: Treatment of ringworm by s/c injection of culture filtrate suspension in buffaloes and cows.
A. $\quad$ Ear of buffalo calf (1.5 year) with ringworm lesion, round area of hairless, grayish-white color lesion.
B. After first dose of culture filtrate injection, begin of hair growth, diminish area of alopecia.
C. 3week after first dose of culture filtrate, hair grow up and disappear of area of alopecia.

Cattle ringworm is the most common skin disease affecting animals and zoonotic to human. The resistance to antifungal drugs, costs of treatment, control obstacles and public health concern emerging importance for discovery of new compounds of broad spectrum antifungal and low side effects for control of animal ringworm such as vaccination [16]. The overall prevalence of ringworm in cattle and buffaloes in this study was $12.5 \%$ as showed in Table 1 . Nearly prevalence rate of 
$10.75 \%$ in calves in Iran was estimated by [1]. While higher prevalence rates reported by [17] of $32.8 \%$ and $30.4 \%$ in calves respectively. Variation in prevalence rates may related to some factors as management, environmental condition, age and immune status of animal [18]. Table 1 clarified that result of $\mathrm{KOH} 20 \%$ examination in cattle and buffaloes were $73.3 \%$ and $60 \%$ respectively. This in constant with previous study of $[19,20]$ proved that $\mathrm{KOH} 20 \%$ used as good diagnostic tool for ringworm examination. This study used culture filtrate vaccine in field animals suffering from ringworm lesions as injection. The results illustrated a good and significantly improvement and curing of the ringworm lesions by 2 doses of $5 \mathrm{ml} \mathrm{s} / \mathrm{c}$ at 10 days intervals and hair completely grow up within 3 weeks after first dose in ( 7 and 10 buffaloes and cows' calves respectively) with curing rate $71.4 \%$ and $70 \%$ respectively as in Table 2 and Figure 1. Similar result of [21] confirmed the importance and beneficial efficacy of culture filtrate vaccine in treatment of bovine ringworm. Moreover [22] indicated the ability of dermatophytes vaccine as prophylactic measure in disease control. These also supported by early studies of $[23,24]$ they analyzed the results of the application of T. verrucosum vaccine on animals showing clinical signs of ringworm infection which illustrated high recovery rate as therapeutic and immunoprophylactic agent. On the other hand, clove oil was applied daily for 10 successive days in (8 and 15 buffaloes and cows' calves respectively). Healing of lesion was observed in (87.5\% and $80 \%$ respectively) as shown in Table 2 and Figure 2. Clove oil from Syzygium aromaticum and eugenol have been widely used in folk medicine and have antiseptic, analgesic and anesthetic characters. Previous study of [25] proved that Clove oil and its active principle (eugenol) have tested for antifungal activity in animal models. Lo' pez et al. [26] found that clove oil possesses significant scavenging inhibition of dermatophytes species [27]. Ahlam et al. [28] through destructive changes in cell membrane composition. This supported by [29] concluded that clove oil has strong antifungal effect against dermatophytosis in animal models and such effect due to components such as Eugenol.

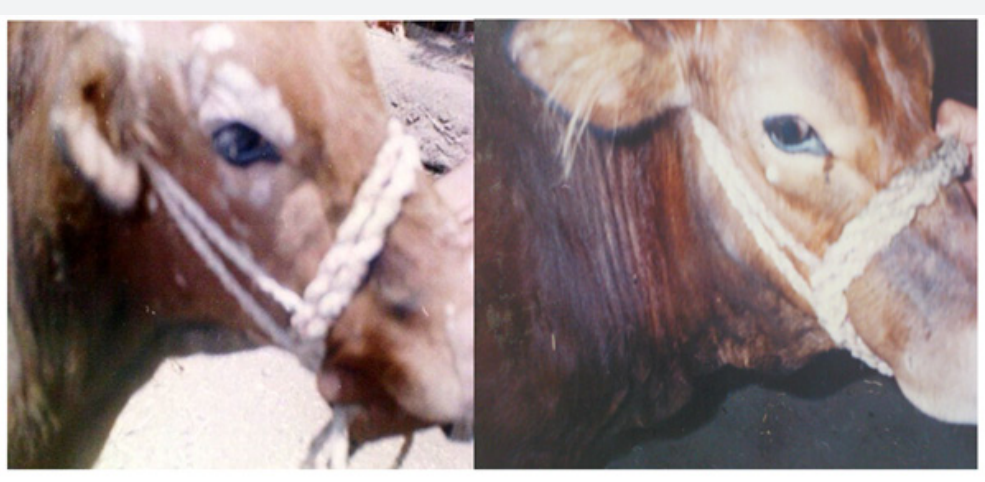

A

Figure 2: Field treatment of ringworm by clove oil.

A. Calf of 1year suffering from ringworm in face and around eyes before clove oil application

B. After 10 days treatment with clove oil, complete healing of lesion.

\section{Conclusion}

This study spot highlights on new compounds that can be used in treatment of ringworm in cattle and buffaloes. Clove oil had a highly antifungal activity against dermatophytes infection as a local spray. Moreover, culture filtrate vaccine exhibited strong fungicidal action on ringworm cases in cattle and buffaloes calves.

\section{Acknowledgment}

Authors wish to express their great thanks for Dr/ Reda Kader a Veterinarian for his valuable help in this work.

\section{References}

1. Aala F, Yusuf UK, khodavandi A, Jamal F (2010) In vitro antiactivity of allicin alone and in combination with two medications against six dermatophytic fungi. Afr j Microbiol Res 4(5): 380-385.

2. Weitzman I, Summerbell RC (1995) The dermatophytes. Clinical. Microbiology Reviews 8(2): 240-259.

3. Woodfolk JA (2005) Allergy and dermatophytes. Clinical. Microbiology Reviews 18(1): 30-43.
4. Murray PR, Rosenthal KS, Pfaller MA (2005) Medical Microbiology. Elsevier Mosby p. 5.

5. Shams-Ghahfarokhii M, Mosleh-Tehrani F, Ranjbar-Bahadori S, Razzaghi Abyaneh M (2009) An epidemiological survey on cattle ringworm in major dairy farms of Mashhad city. Eastern Iran, Iran J Microbiol 1(3): 31-36.

6. Deshmukh SK, Verekar SV, Shrivastav A (2010) The occurrence of keratinophilic fungi in selected soils of Ladakh. India, Nature 2(11): 1247-1252.

7. Radostits OM, Blood DC, Gay CC (1997) Veterinary Medicine. ( $8^{\text {th }}$ edn,) Bailliere Tindall, London, UK, pp. 381-390.

8. Chaieb K, Hajlaoui H, Zmantar T, Kahla-Nakbi AB, Mahmoud R, et al. (2007) The chemical composition and biological activity of clove essential oil. Eugenia caryophyllata (Syzigium aromaticum L. Myrtaceae): a short review. Phytother Res 21(6): 501-506.

9. Rana IS, Rana AS, Rajak RC (2011) Evaluation of antifungal activity in essential oil of the Syzygium aromaticum (L.) by extraction, purification and analysis of its main component eugenol. 42(4): 1269-1277.

10. Calina D, Rapuntean G, Fit N, Nadas G, Olariu R (2010) Aspects regarding immune prophylaxis enzootic bovine ringworm. Cercetari Agronomice Moldova 1(141): 73-78. 
11. Ellis D, Davis S, Alexiou H, Handke R, Bartley R (2007) Description of medical fungi. 2ndEdition the National Library of Australia.

12. Rippon JW (1998) Medical Mycology, the pathogenic fungi and the pathogenic Actinomycetes. ( $3^{\text {rd }}$ edn), WB Saunders Co, Philadelphia, USA.

13. Cheesbrough M (2003 Distinct laboratory practical in tropical countries, part 2 Cambridge University press, and UK pp. 136.

14. Collee JG, Duguid JP, Fraser AG, Marmion BP, Simmons A (1996) Mackie and McCartney Practical Medical Microbiology. $\left(14^{\text {th }}\right.$ edn), The English Language Book Society and Churchill Living Stone Edinburgh and New York, USA

15. De Boer DJ, Moriello KA (1993) Humoral and cellular immune responses to Microsporum Canis in naturally occurring feline dermatophytosis. J Med Vet Mycol 31(21): 121-132.

16. Chermette R, Ferreiro L, Guillto J (2008) Dermatophytoses in animals. Mycopathologia 166: 385-405.

17. Al-Ani FK, Younes FA, Al-Rawashdeh OF (2002) Ringworm Infection in Cattle and Horses in Jordan. Acta Vet Brno 71: 55-60.

18. Moretti A, Boncio I, Pasquail P (1998) Epidemiological aspects of dermatophytes infections in horses and cattle. Zentralbl Veterinamed B 45(4): 205-208

19. Akbarmehr J (2011) The prevalence of cattle ringworm in native dairy farms of Sarab city (East Azerbaijan province), Iran. African Journal of Microbiology Research 5(11): 1268-1271.

20. El-diasty EM, Ahmed MA, Nagwa O, Salwa FM, Samaa IE, et al. (2013) Antifungal activity of zinc oxide nanoparticles against dermatophytic lesions of cattle. Romanian J Biophys 23(3): 191-202.
21. Arslan HH, Yarim GF, Yavuz O, Bas B (2007) Positive effects of attenuated Trichophyton verrucosum strain administration in treatment of the bovine trichophytosis. Revue Med Vet 158 (10): 509-513.

22. Bredahl L, Gyllensvaan C (2000) Incidence and control of cattle ringworm in Scandinavia. Mycoses 43(1): 8-10.

23. Ollhoff RD, Siesenop U, Bohm KH (1997) The therapeutic use of the live vaccine Permavax- Tricho against cattle ringworm. Praktische Tierarzt, 78(9): 762-771

24. Tirziu E, Decun M (1999) Cattle enzootic ringworm Prophylaxis and control with Trichovac. Medicina Veterinara 9(4): 375-381.

25. Ahmad N, Alam MK, Shehbaz A, Khan A, Mannan A, et al. (2005) Antimicrobial activity of clove oil and its potential in the treatment of vaginal candidiasis. J Drug Target 13: 555-561.

26. Lopez P, Sanchez C, Batlle R, Nerın C (2005) Solid and vapour phase antimicrobial activities of six essential oils: susceptibility of selected foodborne bacterial and fungal strains. J Agric Food Chem 53: 69396946.

27. Chee HY, Lee MH (2007) Antifungal activity of clove essential oil and its volatile vapour against dermatophytic fungi. Mycobiol 35(4): 241-243.

28. Ahlam K, Hanaa AW, Abd-El Khaliq MM (2013) The effect of clove oil on Staphylococcus aureus and dermatophytes isolated from skin affections in buffaloes.12th Sci. Cong., Egyptian Society for Cattle Diseases, Hurgada, Egypt.

29. Zuzarte M, Gonçalves MJ, Canhoto J, Salgueiro L (2011) Antidermatophytic activity of essential oils. Science against microbial pathogens: communicating current research and technological advances A. Méndez-Vilas (Ed.) FORMATEX.

This work is licensed under Creative

Commons Attribution 4.0 License

DOI: $10.19080 / J D V S .2018 .07 .555708$ 